\title{
FOREWORD
}

\author{
William Grabe
}

\section{ARAL XI RATIONALE}

In the course of the first decade of the Annual Review of Applied Linguistics, discourse analysis has been the focus of one entire volume and many chapters in other volumes. Volume III (1983) was devoted primarily to contrastive written discourse, and various chapters in Volumes V, VII, VIII, $\mathrm{IX}$, and $\mathrm{X}$ covered a wide range of discourse analyses and applications in applied linguistic contexts; these contributions covered stylistics and approaches to written discourse, writing in a second language, discourse analysis in second language acquisition, discourse analysis in professional contexts, discourse approaches to language teaching, and research on literacy development. The broad implications to be drawn from this relationship between discourse analysis and applied linguistics is that discourse analysis constitutes a, if not the, crucial research foundation for applied linguistics.

Over the last ten years, discourse analysis itself has evolved to the point at which it is emerging as a discipline in its own right, rather than being viewed primarily as a set of disparate research techniques and approaches. A number of contributors to this volume have made note of the discussions about discourse analysis-some at cross-purposes-which appeared in the tenth anniversary issue of the journal Text (1990). In addition, Tannen's (1990) commentary in the Text issue, which calls for celebrating the diversity of discourse theories and methods, is taken up by a number of contributors as well. Indeed, in one respect, this Volume of $A R A L$ does celebrate the diversity of discourse analysis.

At the same time, a primary motivation for the current Volume is to draw together different perspectives in discourse analysis in order to identify important commonalities in theory and application. A careful reading of this Volume should, in fact, reveal convergent principles. The clearest evidence of this is the conceptual and citational intertextuality running through the 
contributions by Celce-Murcia, Poole, Riggenbach, Schiffrin, and Shohamy, as well as through Atkinson, Bazerman, Beaugrande, Connor, Kress, Short, and Swales. Even the apparent division between spoken and written discourse is bridged by the near-universal emphasis on the social and political forces underlying language use. Kaplan, in his summary to the Volume, implicates this notion in his synthesis of approaches presented by various contributors.

There is no doubt that a close relationship exists between discourse analysis and applied linguistics; virtually all of second language acquisition research and language education instruction assumes principles which are dependent on discourse analysis research. For this reason, the goal to develop a consensual view on the uses and applications of discourse analysis is crucial; a more coherent synthesis of discourse analysis will lead to more effective research in applied linguistics. As Swales suggests in his article, we must find ways not to miss so many rich implications from the discourse data. In order to seek greater consensus, then, this Volume brings together a wide range of approaches to, and applications of, discourse analysis.

The Volume is divided into two sections: 1) Foundations of Discourse Analysis, and 2) Applications of Discourse Analysis-both in professional and educational contexts. From the perspective of the Editorial Board, there is one important gap in the foundations section; there is no chapter on cross-cultural aspects of discourse analysis. Nessa Wolfson had agreed to contribute this chapter, but her untimely death prevented her from doing so. Speaking for the Editorial Board, we are sure that her contribution would have added significant insights to this Volume. We will miss her for this, and for all her other contributions to sociolinguistics and applied linguistics.

\section{PROCEDURAL NOTES}

In all sections, internal notes use parenthetical citation. All bibliographic entries follow the basic format of the Linguistic Society of America [LSA], although a somewhat unique citation form is emerging for the $A R A L$ series. With respect to internal citation, the two types of bibliographies-annotated and unannotated-should be viewed as integrated, so that in instances where there is more than one entry for a given author for a particular year (e.g., 1980a; 1980b), it is possible that either of the entries may occur in either of the bibliographies; that is, 1980a may be in the annotated bibliography while $1980 \mathrm{~b}$ may be in the unannotated bibliography, or vice versa. No items are duplicated between the two separate bibliographic lists; that is, the item identified as $1980 \mathrm{a}$ will not occur in both the annotated and the unannotated bibliography. Both types of bibliography-annotated and unannotated-are arranged in strict alphabetical order by the last name of the first author; that is, all the works authored by a particular individual will appear before all the works edited by the same author, and both of those entry types will precede works co-authored or co-edited by that same author (or set 
of authors) are indicated by the use of a solid line [ ] of the same length as the name (or names) it replaces. Sources that include cited articles may not necessarily be represented in either bibliographic list if they are not in general germane to the particular area under discussion; in general, belletristic works cited as examples (or for more literary purposes) are not included in either bibliographic list, though they are identified in detail in the article in which they occur. In a few instances, where special bibliographic sets are included (e.g., legal citations), a separate list of the special references is included. In all texts contributed to the $A R A L$ series, an editorial effort has been made to conform generally to the usages and spellings common in the United States. Where possible, English translations of all non-English sources are provided. All contributed papers have been composed specifically for publication in the $A R A L$ series and have not (unless otherwise specifically noted) appeared elsewhere previously, although their contents may have been used in whole or in part in oral presentations by the author(s).

The Editorial Directors do not assume responsibility for the positions taken by contributors. Contributions often involve issues of policy as well as more clearly language-related issues. The Editorial Directors wish to be held blameless for opinions and errors of fact expressed by any contributor. The Editor apologizes in advance for any editorial errors that may have crept into the texts and accepts full responsibility for any such editorial errors, but not for substantive errors which are the sole responsibility of each contributor. Bibliographies are prepared and submitted by the contributors; the Editor makes every effort to assure the accuracy of each bibliographic entry that appears in every volume of $A R A L$, but in the case of materials not readily available through libraries or other bibliographic sources in the United States, the Editor is dependent upon the accuracy of material submitted by the contributors. In some few instances, inclusive pages for cited articles, which originally appeared in anthologies or collections, are not given; such omissions occur only when the original source is not available to the Editor and/or when the contributor has not supplied the appropriate pagination. In more recent volumes, every effort has been made, in connection with the citation of theses and dissertations, to provide a reference number for Dissertation Abstracts. In materials listed in well-known storage and retrieval networks like ERIC and the British Council's ELT Documents, reference numbers are also provided; when titles available only through electronic data bases are cited, every effort is made to provide an accession number (e.g., as in the ERIC files).

This eleventh volume of $A R A L$ continues the practice, first established in the third volume, of including a running index of authors cited and topics covered in previous issues of $A R A L$. However, this list has become so large that it has become necessary to eliminate the listings from the earliest volumes. Thus, Volume VI (covering 1985) included a cumulative bibliography of Volumes I through V; beginning with Volume VII (covering 1986), as each new year is added, the oldest year's citations have been 
dropped from the list. In this issue (Volume XI, covering 1990), the cumulative citation listing will include citations from Volumes VI through $\mathrm{X}$. Beginning with Volume V, a Contributor Index was added to the series; in each issue, all previous contributors to $A R A L$ are indexed in a single alphabetical list. There has not been a need to curtail this list; thus, it is complete for the entire series. There is also a subject index.

The indices are presented separately-an Author Index, a Subject Index, and a Contributor Index - at the end of each Volume. The Author Index cites every item that has appeared in the bibliographies accompanying each article. Each author citation is accompanied by one or more Roman numerals and Arabic numbers (e.g., Zeydel, E. II/160.) The Roman numeral represents the number of the $A R A L$ Volume in which the author is cited, and the Arabic number represents the page(s) in that Volume on which the citation occurs. Thus, II/160 means that Zeydel is cited in ARAL $I I$ (the Volume published in 1982, covering the work of the year 1981). (Volume I, covering the research in the calendar year of 1980, was published (copyright date) in 1981; Volume II in 1982, etc.] Multiple sets of numbers (e.g., Valdman, A. $\mathrm{aI} / 23, \mathrm{aI} / 102, \mathrm{I} / 106)$ mean that the author is cited in more than one place. The prefixed lower case a (e.g., in al/23) indicates that the citation occurs in an annotated bibliography. Unmarked cases occur in unannotated bibliographies. U.S. government publications, court decisions, and public laws are listed separately at the end of the Author Index. To the extent that ARAL may be said to represent the field accurately, the Author Index may become a citation index for use in merit and promotion evaluation in U.S. institutions.

The Subject Index provides the traditional alphabetical list of topics covered, giving inclusive pages by volume for the point at which the discussion occurs (e.g., II/106-123); this entry indicates that the subject is covered on pp. 106-123 in Volume II. Multiple number sets (e.g., Microsociolinguistics: $\mathrm{I} / 181-196, \mathrm{~V} / 47-48$ ) indicate that the subject (microsociolinguistics, in this case) is discussed in two places in the series, once in Volume I on pp. 181-196, and again in Volume $V$ on pp. 47-48.

The Contributor Index provides a traditional alphabetical listing of all contributors to the $A R A L$ series since the beginning of the series. The citation includes the complete title of the contribution as well as the name of the contributor. Each entry, as in the other Indices, carries two designations (e.g., II/129); the first number designates the Volume in which the contribution occurs (in this case Volume II), and the second number indicates the page in that Volume on which the contribution begins.

It is the intent of the Editor-in-Chief to continue the several indices in future volumes of this series. It has been suggested that a complete bibliography of all works cited in $A R A L$ might constitute a useful contribution to the field; such a bibliography, published as a separate volume, would both offer a compendium of works considered important enough to cite by authors 
who are, presumably, experts in the various sub-fields of applied linguistics, and serve as the beginning of a citation index for the field. There are, obviously, a number of problems in compiling such a bibliography, since items listed as "in press" or "forthcoming," which have subsequently been published, would need to be corrected, inclusive pages would need to be added, and items which have never appeared would have to be cited in a modified format. This is a massive undertaking. The Editorial Board seeks the views of scholars in the field. Comments would be welcome on the desirability of compiling such a bibliography.

\title{
ACKNOWLEDGEMENTS
}

As the incoming Editor of $A R A L$, I would like to thank the previous Editor, Robert Kaplan, and his Editorial Assistant, Audrey Kaplan, for the many hours they have spent to facilitate a smooth editorial transition. In my first year as Editor, I have relied continually on Robert Kaplan and other members of the Editorial Board for advice and assistance, and I thank them sincerely. I also need to thank Robert Kaplan and Fredricka Stoller for standing in during a part of the editorial process while I was on a Fulbright grant for five months in Brazil. They both were happy to see me return!

Closer to home, I would like to thank my Editorial Assistant, Beth Yule, for all the extra time and effort that was required to start up a journal in a new location. It has been a learning experience for both of us, and she has kept her sense of humor throughout the entire process. I would like to thank Ann Beck and Randi Gilbert for proofreading the manuscript and pointing out many editorial matters which I had overlooked. I would also like to thank Maureen McAuliffe, for computer consultation, for editorial assistance, and for putting the final copy through a page-maker program. Finally, I would like to acknowledge the support and assistance of the Cambridge University Press, as well as the Department of English and the College of Arts and Sciences at Northern Arizona University, which have provided the Editor with the basic facilities and have absorbed some of the incidental costs associated with the production of this Volume.

Tannen, D. 1990. Discourse analysis: The excitement of diversity. Text. 10.1/2.109-111.

\author{
William Grabe \\ Flagstaff, Arizona \\ January, 1991
}

